\title{
Effect of wear of diamond wire on surface morphology, roughness and subsurface damage of silicon wafers
}

\author{
Arkadeep Kumar $^{\text {a }}$, Steffi Kaminski ${ }^{\text {, }}$, Shreyes N. Melkote ${ }^{a}$, Chris Arcona ${ }^{b}$ \\ ${ }^{a}$ George W. Woodruff School of Mechanical Engineering, Georgia Institute of Technology, \\ Atlanta, Georgia, USA. \\ ${ }^{b}$ Saint-Gobain Northboro R\&D Center, Northborough, MA, USA. \\ Corresponding author: arkadeepkumar@gatech.edu
}

\begin{abstract}
Wear of fixed abrasive diamond wire affects the quality of sliced silicon wafers, necessitating replacement of the costly wire. This paper analyzes the effect of wire wear on the surface morphology, roughness, and subsurface damage of as-cut single crystal silicon wafers. Scanning electron microscopy, confocal microscopy, and focused ion beam machining (FIB) are used to evaluate the surface morphology, areal surface roughness, and subsurface damage (cracks). Results show that, with increased wire wear, the wafers exhibit greater evidence of ductile removal, lower surface roughness, fewer but slightly deeper subsurface cracks, and lower average fracture strength.
\end{abstract}

Keywords: wear; diamond; wire sawing; silicon wafer; surface; subsurface; damage

\section{Introduction}

Silicon wafers for photovoltaic solar cells are manufactured by wire sawing processes, which slice mono-crystalline silicon ingots produced by the Czochralski $(\mathrm{Cz})$ process or multicrystalline silicon produced by the casting process. In recent years, there has been a shift from loose abrasive slurry wire sawing (LAS) to fixed abrasive diamond wire sawing (DWS), a trend that is forecast to grow [1]. While LAS involves cutting silicon by the abrasive action of loose silicon carbide $(\mathrm{SiC})$ particles in a polyethylene glycol based slurry poured onto a stainless steel wire web, DWS uses diamond grits fixed to the steel wire with electroplated nickel or resin as the bonding agent, and a water based cutting fluid. DWS is advantageous over LAS as it provides increased material removal rate and lower silicon loss due to a smaller kerf. LAS involves three-body abrasion [2-4] of the wire, SiC grit, and silicon, leading to wear of the wire core. In comparison, DWS involves material removal by a two-body abrasion mechanism where the core metal wire is less likely to be worn. Other multi-wire sawing processes involve abrasive based electrochemical methods [5], and resinous diamond wire [6]. In a previous study, electroplated diamond wire manufactured by felt brushes showed better wear resistance [7]. The phenomenon of diamond wire break-in during initiation of cutting and its effect on process performance has been studied recently [8]. Related work on the prediction of diamond wire wear [9] and lifetime estimation has been also reported [10]. High stresses in cutting brittle materials by diamond wire has been shown to induce graphitization of the diamond abrasives [11]. Other studies of cutting single crystal silicon with diamond tools have shown tool wear to influence the 
nanoscale ductile cutting behaviour of silicon [12]. In particular, groove wear in nanometric cutting was found to be significant [13-15]. Diamond tool wear is also known to be affected by its crystallographic orientation [16]. While only indirectly related to diamond wire sawing, ductile material removal mechanisms active during abrasive and chemical mechanical polishing (CMP) of silicon wafers have been studied extensively [3, 17-21]. Micro-contact modelling approaches have been used to study wear in CMP [22].

For DWS to be a commercially viable alternative to slurry sawing, DWS has to produce silicon wafers with the required mechanical integrity and strength without increasing cost. Mechanical properties of sliced silicon wafers depend on the wafer surface and subsurface condition [23, 24]. The surfaces of as-cut wafers have saw damage in the form of grooves, pits, and micro-cracks [24-27]. To reduce the cost of saw damage removal, wafers with minimal surface and subsurface damage are needed. The surface and subsurface damage depend on the condition of the diamond grits. The diamond grits undergo wear due to the high speed sliding contact of the wire with silicon. Thus, the surface and subsurface conditions of as-cut silicon wafers depend on wear of the diamond wire. This paper investigates the effects of diamond wire wear on the surface morphology, surface roughness, and subsurface damage of full-size silicon wafers.

\section{Experimental details}

Mono-crystalline silicon wafers of (100) crystal orientation, and $125 \mathrm{~mm} \mathrm{X} 125 \mathrm{~mm}$ size and 195-200 $\mu \mathrm{m}$ thickness were cut in a reciprocating multi-wire saw using the slicing conditions listed in Table 1. As shown schematically in Figure 1 [28], the new wire spool feeds unused diamond wire into the wire web, which consists of a wire wound in parallel over rollers. The silicon brick is fed into the wire web, thus slicing it into multiple thin wafers. The used wire is taken up by the worn wire spool on the other side.

Table 1. Wafer slicing conditions.

\begin{tabular}{|l|l|}
\hline Parameter & Condition \\
\hline Workpiece & $(100)$ mono-crystalline silicon cut into 700 wafers \\
\hline Wire & $\begin{array}{l}\text { Ni-electroplated diamond wire with } 100 \mathrm{~m} \text { diameter core wire and 8-12 } \mu \mathrm{m} \text { diamond } \\
\text { grits }\end{array}$ \\
\hline Wire speed & $18 \mathrm{~m} / \mathrm{sec}$ \\
\hline Feed rate & $0.8 \mathrm{~mm} / \mathrm{min}$ \\
\hline Reciprocation & $500 \mathrm{~m}$ forward, $490 \mathrm{~m}$ backward \\
\hline
\end{tabular}




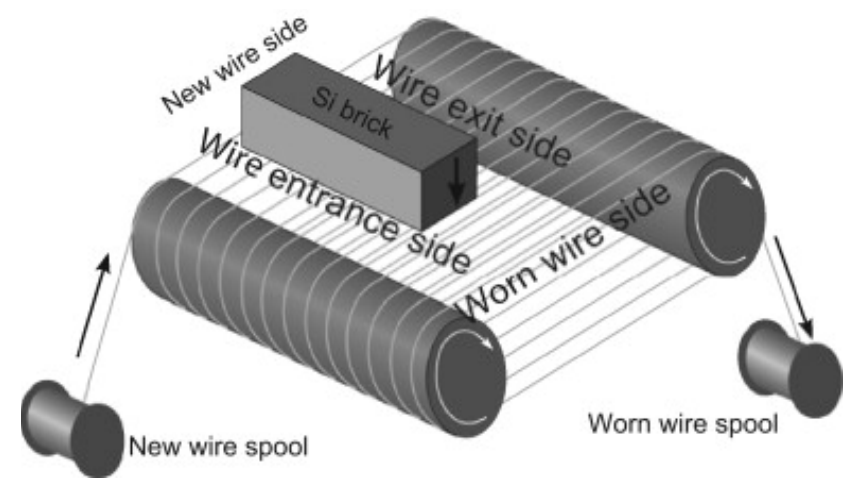

Figure 1. Slicing of a silicon brick using fixed abrasive diamond wire sawing [28].

A single continuous wire was used to cut the wafers from a single silicon brick. In the present study, the sliced wafers were divided into groups based on wire wear. The wear condition of the wire was defined using the contact length, which represents the length of silicon that has interacted with the wire during the slicing process. The contact length depends on the number of times the wire moves forward and back, from the first wafer to the last wafer cut from the ingot. It is also a function of the new wire feed, the distance between the workpiece and roller, ingot length, pitch distance of the wire web, and the number of wafers cut in each forward stroke. In the present study, the cumulative silicon contact length for wafers cut by the new wire was less than $1 \mathrm{~km}$ whereas the cumulative silicon contact length for the used wire was approximately 12 $\mathrm{km}$. Representative sections of the new and used wire were extracted for analysis.

Wafers cut by the new and used wire sections were examined in a scanning electron microscope (Hitachi SU8230 SEM) to analyze the surface morphology and material removal characteristics. Raman spectroscopy of the cut wafers was done using a dispersive Raman spectrometer (Thermo Nicolet Almega XR). Areal three-dimensional average surface roughness of the two wafer groups was measured using a laser confocal microscope (Olympus LEXT). Subsurface damage was analyzed in a SEM (FEI NOVA) using focused ion beam (FIB) cross sectioning of the wafer surfaces at selected locations. Wear of the diamond wire was analyzed in a SEM (Zeiss Ultra$60)$.

\section{Results and Discussion}

\subsection{Surface morphology}

Representative images of the as-cut wafer surface morphology along with the corresponding Raman spectra are shown in Figure 2. It can be seen that wafers cut by the new wire show greater evidence of brittle fracture, which is characterized by frequent chipping and fractured grooves. In contrast, wafers cut by the used wire show more ductile removal characteristics, which consist of smoother sawing marks with some intermittent chipping, albeit few in number. Diamond wire sawing of silicon is known to be characterized by a mixture of ductile material removal and brittle fracture [24]. Silicon is a brittle material, which, when subjected to compressive stress, undergoes pressure induced phase transformation from crystalline Si-I phase to $\beta$-Sn and other metal-like phases, which give rise to ductile cutting [29, 30]. The stress condition varies at each abrasive grit-material interaction point, and hence a mixture of ductile 
cutting and brittle material removal occurs. Based on the results in Figures 2 and 3, we can hypothesize that the stress conditions for the new wire were such that brittle fracture was more dominant compared to the worn wire case. The corresponding Raman spectra showed a dominant crystalline silicon peak at $520 \mathrm{~cm}^{-1}$ and very weak peaks of phase transformed silicon. In comparison, the wafers cut by the used wire showed stronger peaks of phase transformed silicon in addition to the $520 \mathrm{~cm}^{-1}$ peak. The Raman spectra support the surface morphology observations that wafers cut by the used wire have more ductile regions compared to wafers cut by the new wire. These observations were found to be repeatable at three different points on each wafer examined.
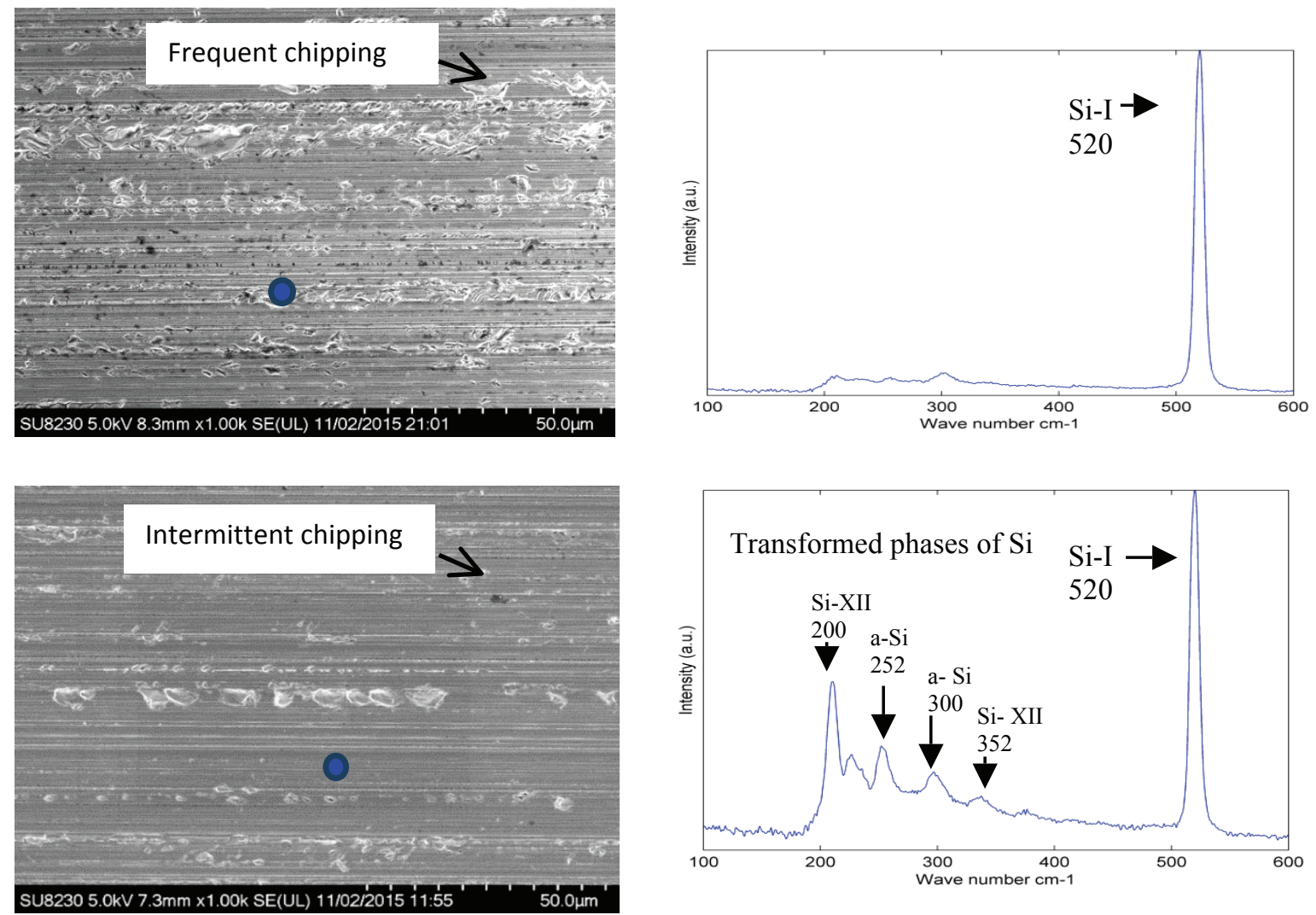

Figure 2. Surface morphology and corresponding Raman spectra of wafers cut by new (top) and used (bottom) sections of the diamond wire.

\subsection{Surface roughness}

Three dimensional (3D) areal surface roughness parameter measurements $\left(\mathrm{S}_{\mathrm{a}}\right)$ were taken at fifteen locations on the wafer surfaces using a $5 \times 3 \operatorname{grid}(130 \mu \mathrm{m}$ X $130 \mu \mathrm{m}$ evaluation area for each location) and averaged. Results (see box plot in Figure 3) show that wafers cut by the new wire have higher average $3 \mathrm{D}$ areal surface roughness $(0.22 \mu \mathrm{m})$ than wafers cut by the used wire $(0.16 \mu \mathrm{m})$. The middle line in the box shows the median, the upper limit shows the upper quartile ( $25 \%$ of values are higher than the upper quartile), and the lower limit shows the lower quartile, with the ends of the whiskers indicating the maximum and minimum values [31]. The results agree with the surface morphology observations, which showed that wafers cut by the new wire 
showed more brittle fracture and chipping, and are therefore expected to have higher roughness than wafers cut by the used wire, which exhibit more ductile behavior. Note that the roughness of wafers cut by the new wire shows more scatter, which is also indicative of random brittle fracture, versus a tighter roughness distribution for the wafers cut by the used wire.

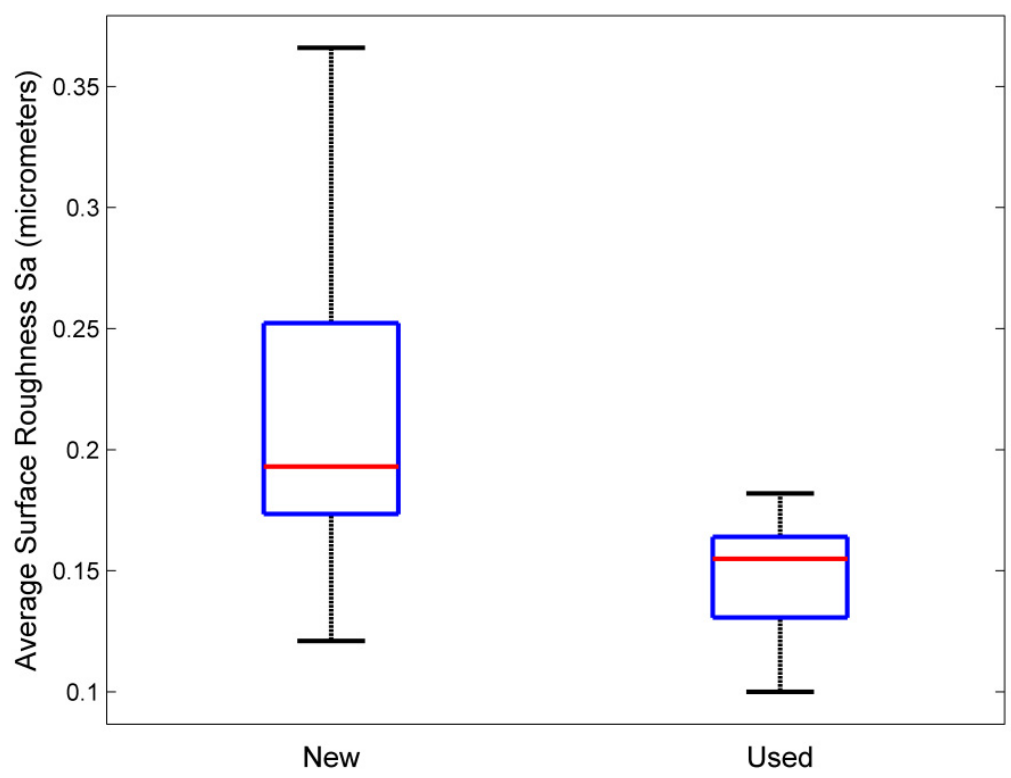

Figure 3. Box plot of surface roughness of wafers cut by new and used wire.

\subsection{Subsurface damage}

Subsurface damage was analysed by cross sectioning the wafers perpendicular to the sawing marks using FIB sections made at 10 locations on the wafer. Figures 4 and 5 show representative images of the subsurface damage in wafers cut by the new and used wire sections, respectively. For wafers cut by the new wire, 9 out of 10 locations showed micro-cracks, whereas in wafers cut by the used wire, only 4 out of 10 locations showed subsurface cracks. Counting the number of cracks per unit length, we found wafers cut by new wire had 0.10 cracks $/ \mu \mathrm{m}$ versus 0.05 cracks/ $\mu \mathrm{m}$ in wafers cut by the used wire. The subsurface cracks in wafers cut by the new wire (see Figure 6) were mostly lateral cracks, with a few median cracks, of $0.6 \mu \mathrm{m}$ mean depth and $1.5 \mu \mathrm{m}$ maximum depth. In wafers cut by the used wire (see Figure 7), the subsurface damage consisted of mostly median cracks (inclined and perpendicular to the surface), with a mean depth of $0.7 \mu \mathrm{m}$ and a maximum depth of $2 \mu \mathrm{m}$. The box plot Figure 6 shows that the mean depth of damage in the two cases are similar, however the scatter is greater in the wafers cut by the used wire compared to the new wire case. A 2-sample t-test of the difference in mean crack depths for the new and used wire cases was found to be statistically insignificant at a 95\% confidence level. However, lateral cracks tend to produce shallow chipping of the wafer surface, whereas median cracks make the wafer more prone to fracture under bending. Hence, even though the number of subsurface cracks in the wafer cut by the used wire is lower, the median/inclined crack geometry makes it more likely to fracture during subsequent handling and processing operations. 

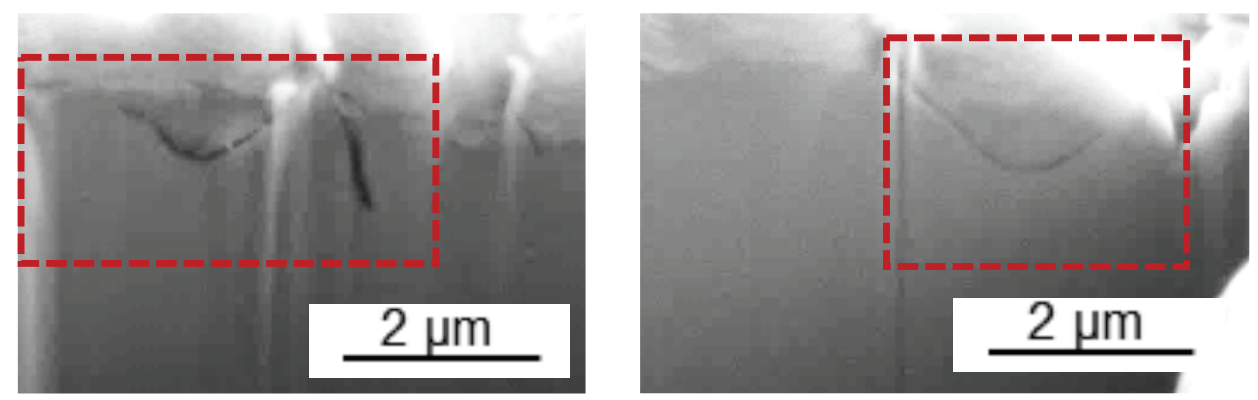

Figure 4. Subsurface damage in wafers cut by the new section of diamond wire; shows curved lateral cracks in most locations. The red boxes highlight the cracks.
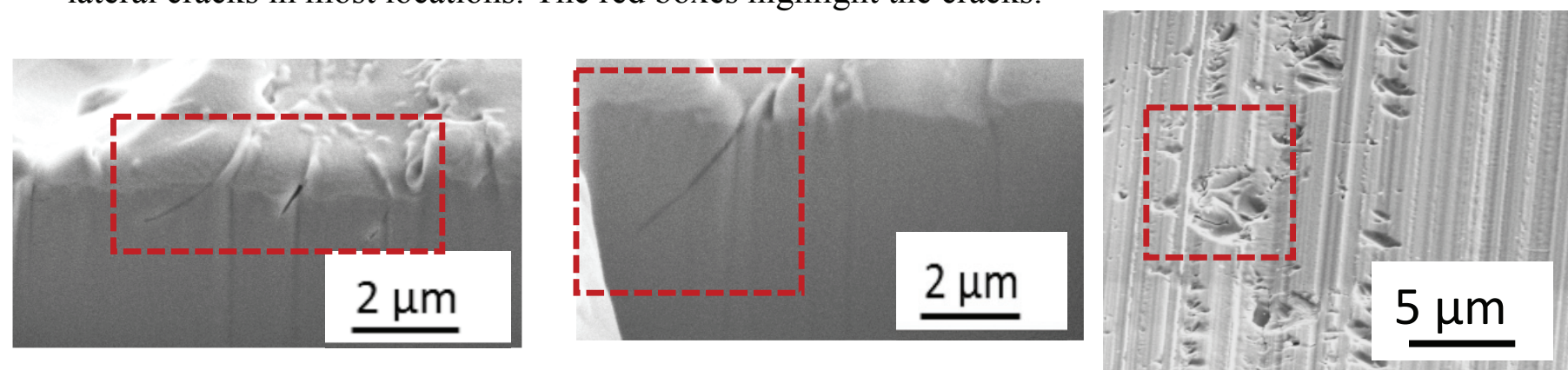

Figure 5. Subsurface damage in wafers cut by the used section of diamond wire; shows minimal damage in some locations but inclined median cracks in other locations. The red boxes highlight the cracks. Image of the wafer surface shows indentation type features below which the median cracks were observed.

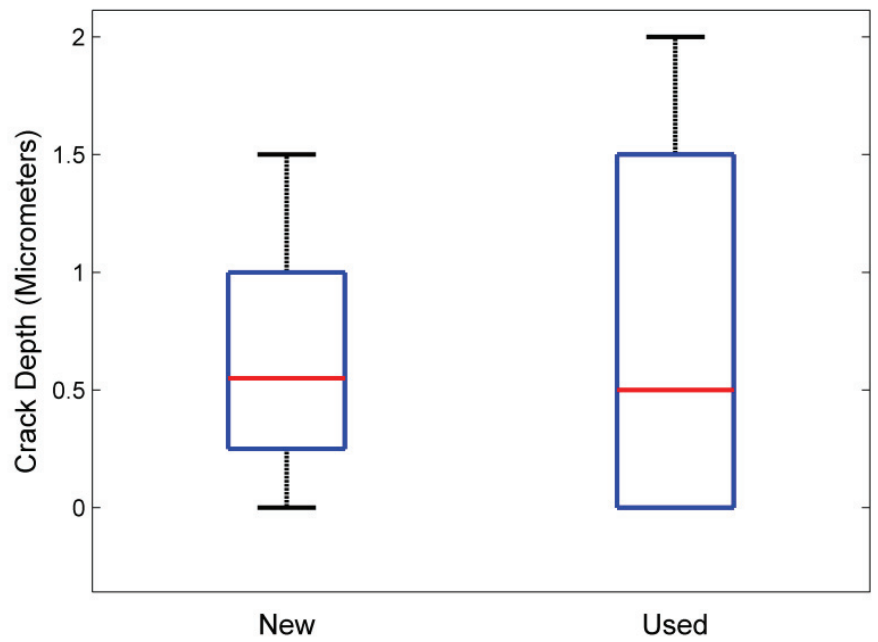

Figure 6. Comparison of crack depths in wafers cut by the new and used wire. 


\subsection{Wire wear}

The new and used sections of the diamond wire were imaged in a SEM. Multiple grits $(\sim 10)$ were imaged, but only representative images are shown. Figure 7 shows abrasive grit images taken from the new wire section. Figure 7(a) shows a grit with some nickel coating still on it, while Figure 7(b) shows an exposed grit. The electroplated nickel coating on the abrasives is removed during initial contact with silicon since nickel (Mohs hardness of 4) is softer than silicon (Mohs hardness of 6-7). The exposed grits in the new wire are mostly intact since the new wire section has had limited contact with the silicon.

As the diamond wire cuts more silicon, the grits become blunt and round due to wear (see Figure 8(a)), and in some cases, due to chipping of the diamond grit (see Figure 8(b)). The grit and silicon contact conditions are sometimes extreme due to the small area of contact. Depending on the load acting on the abrasive, there could be rubbing, ploughing, ductile material removal, or brittle fracture of silicon. Ductile material removal can be achieved through a combination of depth of cut, cutting edge radius, which is influenced by wear of the abrasive, and the force acting on the grit $[32,33]$.

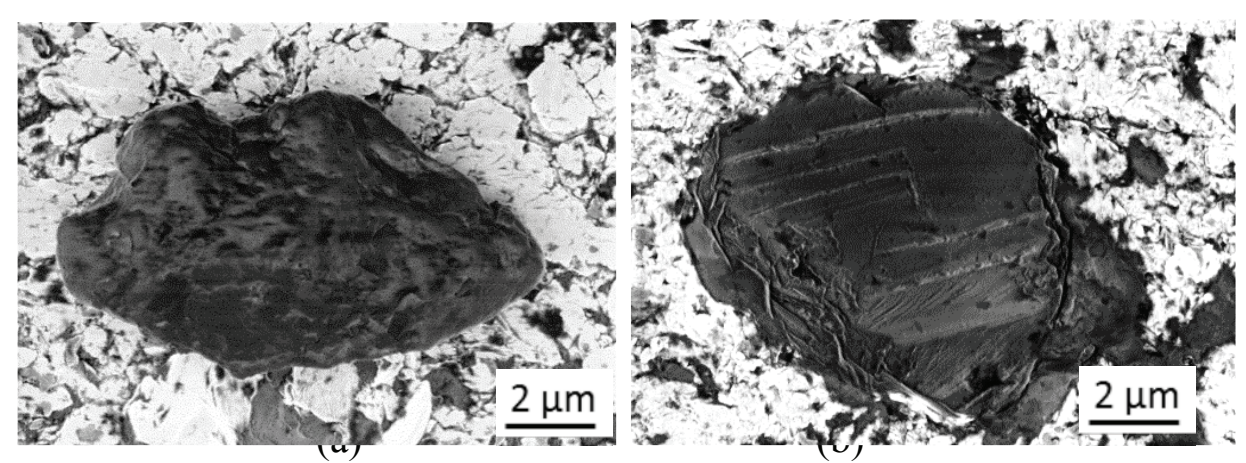

Figure 7. Representative images of the abrasive grit in the new wire section: (a) grit with some nickel coating remaining, and (b) completely exposed grit.

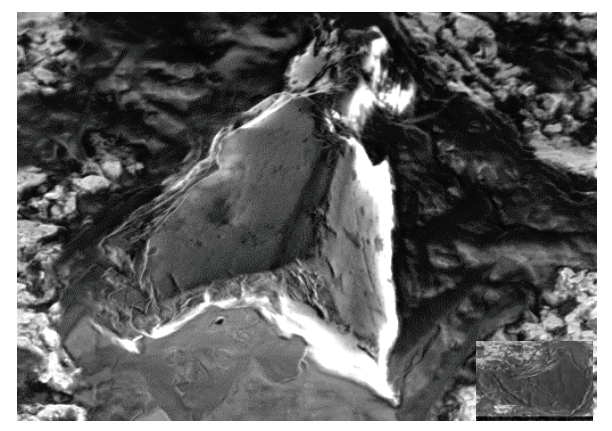

(a)

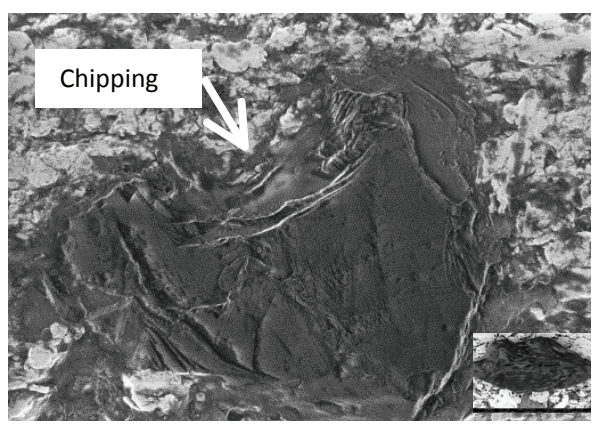

(b)

Figure 8. Representative images of abrasive grit in the used wire section: (a) rounding of sharp edges, and (b) chipping and fracture of abrasive. 


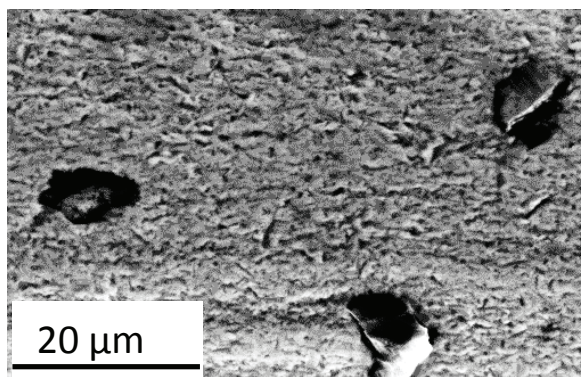

(a)

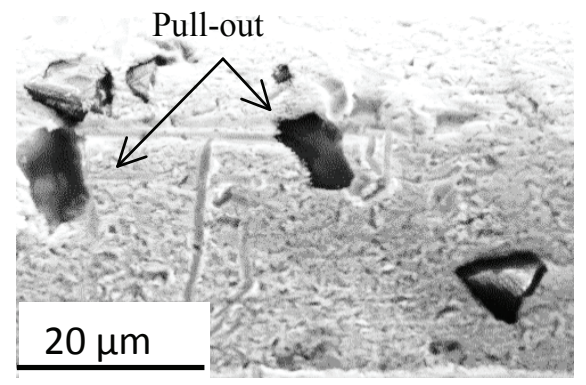

(b)

Figure 9. (a) grits embedded in nickel coating in the new wire, (b) evidence of grit pull-out in the used wire.

The force acting on the grit not only affects the surface and subsurface damage caused in the wafers but also the mechanical integrity of the abrasive. While the new wire shows that diamond grits are still embedded in the nickel coating (see Figure 9(a)), a sufficiently high grit force can cause the grit to be dislodged from the nickel binder leading to 'grit pull-out', as seen in Figure 9(b). We hypothesize that the dislodged abrasives tend to roll around in the cutting channel, and sometimes indent the silicon surface, thereby causing intermittent chipping or the indentation pits seen on the surface of wafers cut by the used wire (see Figure 2). Another likely source of the indentations formed on the wafer surface is wire vibration during sawing, which can cause diamond grits still fixed to the wire to indent the silicon surface. The subsurface median cracks observed in the FIB images in the used wire case were found to be in the vicinity of the indentation marks seen on the wafer surface (as shown earlier in Figure 5). Median crack systems are known to form in indentation [34-36], which could potentially explain the wafer fracture strength results presented in the next section.

Figure 10 shows the EDS results obtained from around a representative grit in the used wire. It shows evidence of silicon debris embedded in the nickel coating. The cutting ability of the wire tends to decrease with increased debris loading of the wire. This phenomenon is analogous to loading of an abrasive grinding wheel, which tends to lower grinding performance.

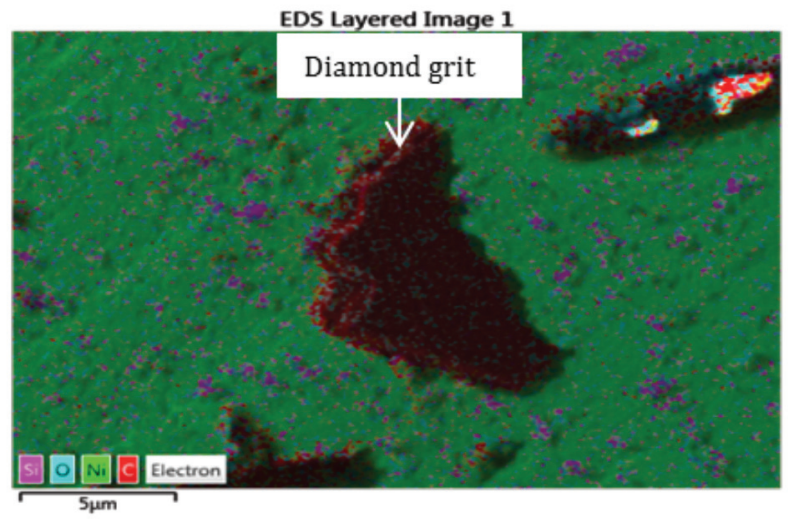

Figure 10. EDS spectra showing silicon embedded (pink) in nickel coating (green). 


\subsection{Fracture strength of wafers}

The fracture strengths of wafers corresponding to the new and used sections of the diamond wire were evaluated using the biaxial flexure method [37]. Circular coupons $35 \mathrm{~mm}$ in diameter were laser-cut from the wafers. Care was taken to ensure that there was minimal edge damage due to laser cutting. The biaxial flexure test apparatus consisted of a ring-on-ring fixture with a loading diameter of $9.5 \mathrm{~mm}$ and a supporting diameter of $20 \mathrm{~mm}$. Twenty three (23) coupons each were taken from wafers sliced by the new and used wire sections and fractured to obtain the fracture strength data shown in Figure 11. It can be seen that the mean fracture strength decreased with wire wear. The difference in the mean strengths of the coupons cut by the new and used wire sections was statistically significant at a $95 \%$ confidence interval. The reduction in the mean fracture strength with wire wear is attributed to the presence of median cracks in the wafers cut by the used wire.

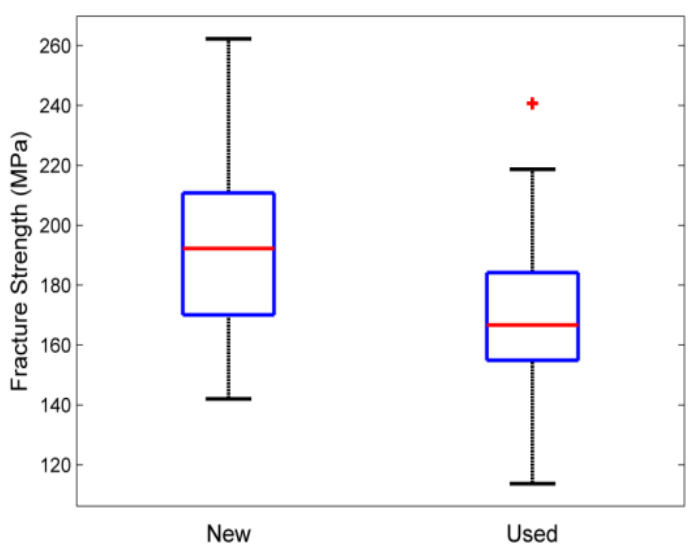

Figure 11. Biaxial fracture strength of wafers cut by new and used wire sections.

\section{Conclusion}

The paper analysed the effects of fixed abrasive diamond wire wear on the surface morphology, roughness, and subsurface damage of (100) mono-crystalline silicon wafers. With wire wear, the wafer surface morphology changed from mostly brittle fracture, which was characterized by frequent chipping and fractured grooves, to more ductile cutting, which was characterized by relatively smooth grooves with intermittent indentations. The average surface roughness and its scatter decreased with wire wear. Analysis of subsurface damage showed that wafers cut with the new wire had more subsurface lateral cracks per unit length than wafers cut with the used wire; however wafers cut with the used wire had comparatively more median cracks, which were produced by the occasional indenting action of loose diamond abrasives dislodged from the diamond wire and moving freely in the kerf. With wire wear, the abrasive grits showed rounding and blunting, with some instances of grit fracture and pull-out. The mean fracture strength of the wafers was lower with wire wear and is attributed to the presence of median cracks, which promote failure of the wafer at a lower stress level. The results reported in this paper provide useful insights into the wear of fixed abrasive diamond wire and its effect on the topographical and mechanical properties of solar silicon wafers. 


\section{Acknowledgements}

The first and third authors are grateful for support of this work by the Saint-Gobain Northboro Research and Development Center and the National Science Foundation (CMMI Grant \#1538293).

\section{References}

[1] ITRPV (2014),"International Technology Roadmap for Photovoltaics " http://www.itrpv.net/Reports/Downloads/2014/,

[2] H. J. Möller (2004),"Basic mechanisms and models of multi-wire sawing," Advanced Engineering Materials, vol. 6, pp. 501-513.

[3] C. Evans, E. Paul, D. Dornfeld, D. Lucca, G. Byrne, M. Tricard, et al. (2003),"Material removal mechanisms in lapping and polishing," CIRP Annals-Manufacturing Technology, vol. 52, pp. 611-633.

[4] A. Bidiville, K. Wasmer, J. Michler, P. M. Nasch, M. Van der Meer, and C. Ballif (2010),"Mechanisms of wafer sawing and impact on wafer properties," Progress in Photovoltaics: Research and Applications, vol. 18, pp. 563-572.

[5] W. Wang, Z. X. Liu, W. Zhang, Y. H. Huang, and D. M. Allen (2011),"Abrasive electrochemical multi-wire slicing of solar silicon ingots into wafers," CIRP Annals Manufacturing Technology, vol. 60, pp. 255-258.

[6] T. Enomoto, Y. Shimazaki, Y. Tani, M. Suzuki, and Y. Kanda (1999),"Development of a resinoid diamond wire containing metal powder for slicing a slicing ingot," CIRP Annals Manufacturing Technology, vol. 48, pp. 273-276.

[7] Y. Chiba, Y. Tani, T. Enomoto, and H. Sato (2003),"Development of a high-speed manufacturing method for electroplated diamond wire tools," CIRP Annals - Manufacturing Technology, vol. 52, pp. 281-284.

[8] S. Lee, H. Kim, D. Kim, and C. Park (2015),"Investigation on diamond wire break-in and its effects on cutting performance in multi-wire sawing," The International Journal of Advanced Manufacturing Technology, pp. 1-8.

[9] K. Sunder, H. Uhle, S. Knöppel, and O. Anspach (2013),"Prediction of wire wear, wire bow and wafer total thickness variation in the diamond wire wafering process," Proceedings of the 28th European PV Solar Energy Conference and Exhibition, pp. 1491 - 1495.

[10] D. Kim, H. Kim, S. Lee, T. Lee, and H. Jeong (2016),"Characterization of diamond wirecutting performance for lifetime estimation and process optimization," Journal of Mechanical Science and Technology, vol. 30, pp. 847-852.

[11] J. Yang, S. Banerjee, J. Wu, Y. Myung, O. Rezvanian, and P. Banerjee (2016),"Phase and stress evolution in diamond microparticles during diamond-coated wire sawing of Si ingots," The International Journal of Advanced Manufacturing Technology, vol. 82, pp. 1675-1682.

[12] X. P. Li, T. He, and M. Rahman (2005),"Tool wear characteristics and their effects on nanoscale ductile mode cutting of silicon wafer," Wear, vol. 259, pp. 1207-1214.

[13] K. Cheng, X. Luo, R. Ward, and R. Holt (2003),"Modeling and simulation of the tool wear in nanometric cutting," Wear, vol. 255, pp. 1427-1432.

[14] M. B. Cai, X. P. Li, and M. Rahman (2007),"Characteristics of "dynamic hard particles" in nanoscale ductile mode cutting of monocrystalline silicon with diamond tools in relation to tool groove wear," Wear, vol. 263, pp. 1459-1466. 
[15] M. B. Cai, X. P. Li, and M. Rahman (2006),"Study of the mechanism of groove wear of the diamond tool in nanoscale ductile mode cutting of monocrystalline silicon," Journal of Manufacturing Science and Engineering, vol. 129, pp. 281-286.

[16] M. Sharif Uddin, K. H. W. Seah, X. P. Li, M. Rahman, and K. Liu (2004),"Effect of crystallographic orientation on wear of diamond tools for nano-scale ductile cutting of silicon," Wear, vol. 257, pp. 751-759.

[17] R. Komanduri (1996),"On material removal mechanisms in finishing of advanced ceramics and glasses," CIRP Annals - Manufacturing Technology, vol. 45, pp. 509-514.

[18] R. Komanduri, D. A. Lucca, and Y. Tani (1997),"Technological advances in fine abrasive processes," CIRP Annals - Manufacturing Technology, vol. 46, pp. 545-596.

[19] W. J. Liu, Z. J. Pei, and X. J. Xin (2002),"Finite element analysis for grinding and lapping of wire-sawn silicon wafers," Journal of Materials Processing Technology, vol. 129, pp. 2-9.

[20] J. Xin, W. Cai, and J. A. Tichy (2010),"A fundamental model proposed for material removal in chemical-mechanical polishing," Wear, vol. 268, pp. 837-844.

[21] Z. J. Pei and A. Strasbaugh (2001),"Fine grinding of silicon wafers," International Journal of Machine Tools and Manufacture, vol. 41, pp. 659-672.

[22] Y. Zhao and L. Chang (2002),"A micro-contact and wear model for chemical-mechanical polishing of silicon wafers," Wear, vol. 252, pp. 220-226.

[23] A. Chandra, G. Anderson, S. Melkote, W. Gao, H. Haitjema, and K. Wegener (2014),"Role of surfaces and interfaces in solar cell manufacturing," CIRP Annals - Manufacturing Technology, vol. 63, pp. 797-819.

[24] E. Cai, B. Tang, W. R. Fahrner, and L. Zhou (2011),"Characterization of the surfaces generated by diamond cutting of crystalline silicon," 26th European Photovoltaic Solar Energy Conference and Exhibition, pp. 1884 - 1886.

[25] Z. Zhang, B. Wang, R. Kang, B. Zhang, and D. Guo (2015),"Changes in surface layer of silicon wafers from diamond scratching," CIRP Annals - Manufacturing Technology, vol. 64, pp. 349-352.

[26] A. Bidiville, Heiber, J., Wasmer, K., Habegger, S., Assi, F. (2010),"Diamond wire wafering: Wafer morphology in comparison to slurry sawn wafers," Proceedings of 25th European Photovoltaic Solar Energy Conference and Exhibition, pp. 1673 - 1676.

[27] C. G. Scott and S. Danyluk (1992),"Examination of silicon wear debris generated in a linear scratch test," Wear, vol. 152, pp. 183-185.

[28] A. Bidiville, I. Neulist, K. Wasmer, and C. Ballif (2011),"Effect of debris on the silicon wafering for solar cells," Solar Energy Materials and Solar Cells, vol. 95, pp. 2490-2496.

[29] Y. Gogotsi, G. Zhou, S.-S. Ku, and S. Cetinkunt (2001),"Raman microspectroscopy analysis of pressure-induced metallization in scratching of silicon," Semiconductor science and technology, vol. 16, p. 345.

[30] J. Z. Hu, L. D. Merkle, C. S. Menoni, and I. L. Spain (1986),"Crystal data for high-pressure phases of silicon," Physical Review B, vol. 34, pp. 4679-4684.

[31] R. McGill, J. W. Tukey, and W. A. Larsen (1978),"Variations of Box Plots," The American Staistician, vol. 32, pp. 12-16.

[32] H. Tanaka, S. Shimada, and L. Anthony (2007),"Requirements for ductile-mode machining based on deformation analysis of mono-crystalline silicon by molecular dynamics simulation," CIRP Annals - Manufacturing Technology, vol. 56, pp. 53-56. 
[33] K. S. Woon and M. Rahman (2010),"Extrusion-like chip formation mechanism and its role in suppressing void nucleation," CIRP Annals - Manufacturing Technology, vol. 59, pp. 129132.

[34] B. R. Lawn, A. Evans, and D. Marshall (1980),"Elastic/plastic indentation damage in ceramics: the median/radial crack system," Journal of the American Ceramic Society, vol. 63, pp. 574-581.

[35] A. Misra and I. Finnie (1979),"On the scribing and subsequent fracturing of silicon semiconductor wafers," Journal of Materials Science, vol. 14, pp. 2567-2574.

[36] Y. Ahn, T. N. Farris, and S. Chandrasekar (1998),"Sliding microindentation fracture of brittle materials: Role of elastic stress fields," Mechanics of Materials, vol. 29, pp. 143-152.

[37] C. Funke, E. Kullig, M. Kuna, and H. J. Möller (2004),"Biaxial fracture test of silicon wafers," Advanced Engineering Materials, vol. 6, pp. 594-598.

[38] W. Weibull, A statistical theory of the strength of materials: Royal Swedish Institute for Engineering Research, Stockholm, Sweden, 1939. 